\title{
Results of secondary ciliary sulcus fixated posterior chamber intra- ocular lenses in paediatric aphakia
}

\author{
Faruqui S. ${ }^{1}$, Khan M.S. ${ }^{2}$, Jain R. ${ }^{3}$ \\ ${ }^{1}$ Dr. Saba Faruqui, Assistant Professor, Department of Ophthalmology, LN Medical College \& JK Hospital, Bhopal, \\ ${ }^{2}$ Dr. Mohd. Sarfraz Khan, M.S. Ophthalmology, Drishti Eye Care, Bhopal, ${ }^{3}$ Dr. Rahul Jain, M.S. Ophthalmology, Drishti \\ Eye Care, Bhopal, India.
}

Corresponding Author: Dr. Saba Faruqui, HA-74, NRI Colony, VIP Road, Kohefiza, Bhopal. E-mail: saba.faruqui1@yahoo.co.in

\begin{abstract}
Introduction: Primary Intraocular lens implantation is the most preferred method of paediatric cataract management. However there is little literature on secondary correction of aphakia with IOL implantation. Objective: The objective of this study was to evaluate the safety and efficacy of ciliary sulcus implantation of posterior chamber IOLs in cases of paediatric aphakia. Materials and Methods: The charts of 33 patients (52 eyes) ranging from 2-15 years of age, who underwent secondary implantation of PCIOL in the ciliary sulcus between 2016-17 were studied. Those cases that had sufficient capsular support after primary cataract extraction were included. Demographic data was obtained and correlated with the final outcomes in terms of refractive error, post op complications and visual outcome. Results: The final mean visual acuity in $\log$ MAR was $0.64 \pm 0.42$. $43 \%$ of eyes showed good visual acuity $0.4-0.6 \log$ MAR. After surgery $85 \%$ patients with amblyopia showed good visual good response to occlusion therapy. Patients with aphakia operated for traumatic cataract achieved better visual acuity than those with congenital cataract $(0.31 \pm 0.36$ and $0.64 \pm 0.42$ respectively). Mean difference of $-0.06 \mathrm{D}$ was observed between targeted refraction and actual refraction. Conclusions: Patients who had early primary cataract surgery showed better final visual acuity. Our observed complication rate showed that this method of aphakia correction is safe and effective.
\end{abstract}

Keywords: Aphakia, Cataract, Ciliary sulcus fixation, Intra-ocular lens implantation

\section{Introduction}

The most challenging aspect of paediatric cataracts is the visual rehabilitation of the child after surgery rather than the surgery itself. If it is not properly taken care of, an excellently performed cataract extraction may also have a poor outcome as a result of amblyopia, loss of binocularity, development of squint, or formation of a posterior capsular opacification.

Spectacles, contact lenses and posterior chamber IOLs are the various methods of correction of post-operative aphakia, each having their own merits and demerits. Aphakic spectacles have advantages of being cheap and safe but can result in optical problems like induced magnification, visual field restriction and prismatic effect and finally poor compliance, apart from being cosmetically unacceptable. Contact lens can help in avoiding these problems but difficulty in fitting in small

Manuscript received: $14^{\text {th }}$ June 2019

Reviewed: $24^{\text {th }}$ June 2019

Author Corrected: $30^{\text {th }}$ June 2019

Accepted for Publication: $5^{\text {th }}$ July 2019 children and potential risk of microbial keratitis makes them a less suitable alternative. Intraocular lens (IOL) implantation in the pediatric cases is now a generally accepted alternative form of optical correction to contact lenses and spectacles [1]. Secondary IOL has revolutionized the visual rehabilitation of paediatric aphakia as IOL provides full time correction and the optical component closely simulates the correcting capabilities of crystalline lens.

The technical ease and success of secondary IOL implantation depends on capsular support that was left behind at the time of primary cataract surgery. Although the ideal site for IOL implantation is in the bag [2], the ciliary sulcus has been the common site of implantation for many years [3-5]. Certain situations such as secondary IOL implantation, posterior capsular rupture and zonular dialysis make sulcus implantation the preferred option [6]. Awad et al [7] performed an ultrasound biomicroscopy (UBM) on the ciliary sulcus 
in 10 children after unilateral secondary IOL implantation and demonstrated that the structure of the sulcus in the implanted eye appeared similar to the sulcus of the contralateral normal eye. No gross haptic erosion into the sclera, ciliary body, or sulcus was noted. There is sufficient data on the safety profile and success of sulcus fixated IOL in adults [8,9], literature on the same in paediatric population is limited. The present study aimed to answer these questions concerning the safety and efficacy of sulcus fixated posterior chamber IOLs as a means of visual rehabilitation for paediatric aphakia.

\section{Subjects and Methods}

Study setting:Department of paediatric ophthalmology, Gomabai Nethralaya, Neemuch

Duration: August 2016-July 2017

Ethical considerations \& permission: The study followed the tenets of the declaration of Helsinki, was approved by the institutional review board of the center, and was in compliance with the Health Insurance Portability and Accountability Act.

Study type: Retrospective case review of hospital records

Sampling method: Simple random sampling

Sample size: calculated using Cochran's formula included 52 eyes of 33 patients

Inclusion criteria: (1) Aphakic children between ages of 2-15 years

(2) All the cases of congenital, developmental, traumatic cataract that were left aphakic at the time of primary surgery

(3)Those cases that had sufficient capsular support for sulcus implantation of IOL

Exclusion criteria: (1) Eyes that received sclera fixated IOL (2) Uveitic and glaucomatous eyes

Data collection procedure: Demographic and preoperative data were obtained, including age at primary cataract surgery and secondary IOL implantation and cataract etiology. All patients underwent comprehensive ophthalmic examination including slit-lamp examination, corneal diameter, intraocular pressure, pachymetry and axial length measurement. In younger uncooperative patients, keratometry and axial length measurements were performed under general anesthesia immediately before surgery; in older patients the measurements were taken in the out-patient department. Biometry of both eyes was performed in the same session; however, if the second eye surgery was performed more than 1 month later then biometry measurements were repeated.

All biometry measures were obtained by the surgeon; when significant variation between the eyes was found, an independent measure was taken and confirmed by a second surgeon. IOL power was calculated with the SRK II formula. Target refractions varied according to the age at surgery, with residual hyperopic error desired in younger patients or with consideration to the refractive status of the fellow eye.

Surgery was performed by a single surgeon via a standardized technique. In brief, a superior corneoscleral tunnel was made for IOL insertion, in addition to paracentesis at approximately the 10-o'clockand 2o'clock positions. Anterior chamber was formed with sodium hyaluoronate (Healon). In cases with adhesions between posterior surface of iris and posterior capsule, synechiolysis was done. In cases where primary posterior capsulorrhexis became small due to reproliferated lens material and capsular fibrosis, enlargement of primary posterior capsulorrhexis with limited anterior vitrectomy was done.

Then three piece $6 \mathrm{~mm}$ acrylic optic with PMMA haptic IOL (Sensar AR40e, AMO) was implanted in ciliary sulcus. Anterior chamber was formed with BSS. All ports were sutured with 10-0 nylon suture. For all patients, a subconjunctival injection of Dexamethasone with Gentamycin was given at the end of surgery, and topical steroids were prescribed in tapering dose for 1 month.

The main outcome measures were post-operative complications, visual outcome, and refractive error. The occurrence of complications, including corneal edema, increased postoperative inflammation, glaucoma, retinal detachment, and IOL decenteration, was noted. If the intraocular pressure (IOP) was $>25 \mathrm{~mm} \mathrm{Hg}$ and ocular structural changes- such as increased optic nerve cupping or myopic refractive shift-occurred after the early postoperative period, then the patient was considered to have glaucoma.

IOL decentration was recorded if the edge of the IOL optic could be visualized through the undilated pupil or if the IOL/ capsular bag complex was seen to be decentered. Visual outcome was assessed by changes in lines of best-corrected visual acuity, which was measured with correction in the early postoperative 
period. Visual outcomes were compared relative to age and between congenital and traumatic aphakia. Retinoscopy was used to determine postoperative refraction, with refinement by manifest refraction whenever possible. This measure, obtained at 4 weeks postoperatively, was converted into spherical equivalent (sphere $11 / 2$ cylinder). The surgeon's targeted refraction was recorded and spectacle correction with bifocal add for near vision was given. Whenever required amblyopia threrapy was given.
Data Analysis: Data was analysed using the SPSS (Statistical Package for Social Sciences) software. Prediction error (PE) was calculated for each eye as predicted refraction minus actual refraction; absolute PE was calculated for each eye as PE5 (predicted refraction) - (actual refraction). The chi-square test was used to study the difference in final visual outcome in relation to the different variables. Fischer's exact test was used when the count in any of the cells was less than 5 .

\section{Results}

A total of 52 eyes of 33 patients who underwent secondary IOL implantation were evaluated. Unilateral surgery was performed in 14 patients. 40 eyes had congenital cataract and 12 eyes traumatic cataract (Figure 1) Out of 12 eyes, 9 eyes (75\%) had undergone corneoscleral laceration repair at the time of primary cataract surgery. In 3 eyes self-sealed corneal tear was present. Injury with pencil tip was most common mode of injury. Mean age at primary surgery was 7.3 months (range 0.87 to 18.3 months, Table 1) in congenital aphakia group and 83.8 months (range $32-171$ months) in traumatic aphakia group. Mean age at secondary surgery was 43.6 months (range 19.8 to 98.4 months) in congenital aphakia group and 89.2 months (range 40 to 198 months) in traumatic aphakia group. Mean interval between primary cataract extraction and secondary IOL surgery was 36.3 months (range 12.5 to 91 months) in congenital aphakia and 5.7 months (range 1.2 to 26.5 months) in traumatic aphakia group (Table 1). Although patients were advised early secondary IOL surgery, mostly after 2 years of age, delay between primary cataract and secondary IOL surgery reflects delay in patients presenting for second surgery and probably traditional thinking of parents. Traumatic aphakic patients had less delay between primary cataract and secondary IOL surgery. Mean follow up was 14.2 months (range 4.2 months to 53.9 months). (Table 3).

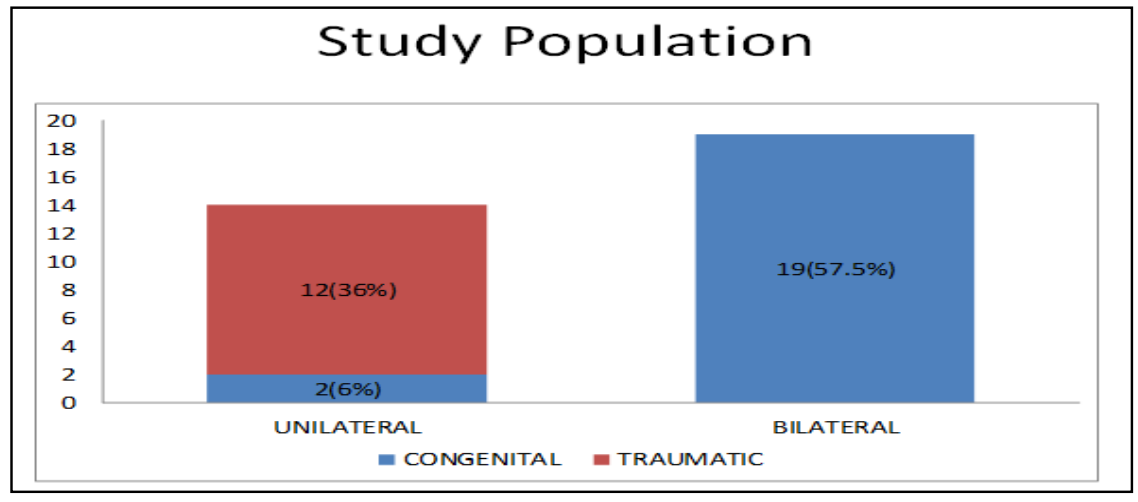

Figure-1: Distribution of cases according to laterality of cataract

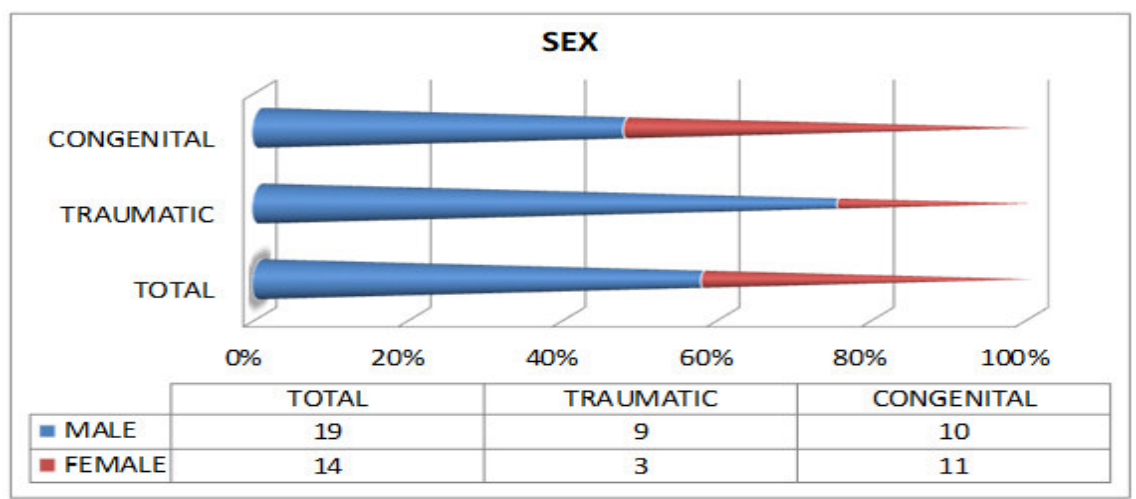

Figure 2: Demographic characteristics 
Original Research Article

Table-1: Baseline characteristics.

\begin{tabular}{|l|c|c|c|}
\hline & Traumatic & Congenital & Total \\
\hline Age in months at primary surgery mean (range) & $83.8(32-171)$ & $7.3(0.87-18.3)$ & $25(0.87-171)$ \\
\hline $\begin{array}{l}\text { Age in months at secondary surgery mean } \\
\text { (range) }\end{array}$ & $89.2(40-198)$ & $43.6(19.8-98.4)$ & $54.15(19.9-198)$ \\
\hline $\begin{array}{l}\text { Duration in months between primary and } \\
\text { secondary surgery mean (range) }\end{array}$ & $5.7(1.2-26.5)$ & $36.3(12.5-91)$ & $29.2(1.2-91)$ \\
\hline Corneal Diameter in mm mean (range) & $11.4(10.5-12)$ & $11(10-12.5)$ & $11(10-12.5)$ \\
\hline
\end{tabular}

Table-2: Baseline Pre-operative data.

\begin{tabular}{|l|c|c|c|}
\hline & Traumatic & Congenital & Total eyes \\
\hline $\begin{array}{l}\text { IOP in mmHg } \\
\text { mean (range) }\end{array}$ & $13.9(10-18)$ & $12.5(8-20)$ & $12.8(8-20)$ \\
\hline $\begin{array}{l}\text { Axial length in mm } \\
\text { mean (range) }\end{array}$ & $23(22-25.6)$ & $21.6(19.1-26)$ & $21.9(19.1-26)$ \\
\hline $\begin{array}{l}\text { Pachymetry in } \boldsymbol{\mu m} \\
\text { mean (range) }\end{array}$ & $533(501-580)$ & $528(462-688)$ & $529(462-688)$ \\
\hline $\begin{array}{l}\text { Keratometry in D } \\
\text { mean (range) }\end{array}$ & $88.5(81.9-94.4)$ & $86.05(78-94)$ & $87.9(78.2-94.2)$ \\
\hline $\begin{array}{l}\text { IOL power in D } \\
\text { mean (range) }\end{array}$ & $20.9(16.5-23.5)$ & $22.1(12-30)$ & $21.8(12-30)$ \\
\hline
\end{tabular}

Table-3: Mean duration of follow-up.

\begin{tabular}{|c|c|c|}
\hline $\begin{array}{c}\text { Total patients } \\
\text { mean (range) months }\end{array}$ & $\begin{array}{c}\text { Traumatic } \\
\text { mean (range) months }\end{array}$ & $\begin{array}{c}\text { Congenital } \\
\text { mean (range) months }\end{array}$ \\
\hline $14.2(4.2-53-9)$ & $17.2(4.2-41)$ & $13.2(4.3-53.9)$ \\
\hline
\end{tabular}

Table-4: Post operative Spherical Equivalent.

\begin{tabular}{|c|c|c|c|c|}
\hline $\begin{array}{c}\text { Spherical } \\
\text { equvalent }\end{array}$ & $\begin{array}{c}\text { Total eyes Mean } \pm \text { SD } \\
\text { (range) dioptre }\end{array}$ & $\begin{array}{c}\text { Traumatic aphakia } \\
\text { Mean } \pm \text { SD (range) dioptre }\end{array}$ & $\begin{array}{c}\text { Congenital aphakia } \\
\text { Mean } \pm \text { SD (range) dioptre }\end{array}$ & $\begin{array}{c}\text { P- } \\
\text { Value }\end{array}$ \\
\hline Preoperative & $16.2 \pm 2.8(10-21.5)$ & $15.3 \pm 2.6(11.5-20)$ & $16.5 \pm 2.9(10-21.2)$ & 0.20 \\
\hline First follow up & $2.0 .3 \pm 2.3(-0.2-+7)$ & $1.68 \pm 2.5(-1.5-+7.0)$ & $2.1(-2.0-+4.0)$ & 0.55 \\
\hline Last follow up & $1.3 \pm 2.3(-6.5-+5)$ & $0.7 \pm 3.2(-6.5-+5)$ & $1.47(-4.0-+4.0)$ & 0.32 \\
\hline
\end{tabular}

Table-5: Prediction error.

\begin{tabular}{|c|c|c|c|c|}
\hline & $\begin{array}{c}\text { Total eyes } \\
\text { Mean } \pm \text { SD }\end{array}$ & $\begin{array}{c}\text { Traumatic aphakia } \\
\text { Mean } \pm \text { SD }\end{array}$ & $\begin{array}{c}\text { Congenital } \\
\text { Aphakia }\end{array}$ & p Value \\
\hline Predicted refraction & $+2.09 \pm 1.14 \mathrm{D}$ & $+1.08 \pm 1.06$ & $+2.4 \pm 0.99$ & \\
\hline Absolute prediction Error & $-0.06 \pm 2.17$ & $-0.60 \pm 2.32$ & $+0.26 \pm 2.11$ & 0.23 \\
\hline
\end{tabular}


Table-6: Final visual outcome.

\begin{tabular}{|c|c|c|}
\hline & Visual acquity LOG MAR Mean \pm SD & p value \\
\hline Total eyes & $0.64 \pm 0.42$ & \\
\hline Traumatic & $0.31 \pm 0.36$ & \\
\hline Congenital & $0.76 \pm 0.38$ & 0.001 \\
\hline
\end{tabular}

Log MAR - Minimum angle of resolution

Table-7: Visual outcome (Traumatic versus Congenital Aphakia).

\begin{tabular}{|c|c|c|c|}
\hline $\begin{array}{c}\text { BCVA } \\
\text { (LOG MAR) }\end{array}$ & $\begin{array}{c}\text { Traumatic } \\
\text { No. }(\%)\end{array}$ & $\begin{array}{c}\text { Congenital } \\
\text { No (\%) }\end{array}$ & $\begin{array}{c}\text { Total eyes } \\
\text { No (\%) }\end{array}$ \\
\hline$<0.3$ & $9(20.4)$ & $3(6.8)$ & $12(27.2)$ \\
\hline $0.4-0.6$ & $2(4.5)$ & $17(38.6)$ & $19(43.2)$ \\
\hline $0.7-0.9$ & & $5(11.3)$ & $5(11.3)$ \\
\hline$\geq 1$ & $1(2.2)$ & $7(16)$ & $8(18.1)$ \\
\hline Total Eyes & $\mathbf{1 2}(\mathbf{2 7 . 2})$ & $\mathbf{3 2}(\mathbf{7 2 . 7})$ & $\mathbf{4 4}$ \\
\hline
\end{tabular}

Table-8: Post-operative complications.

\begin{tabular}{|c|c|c|}
\hline S. No. & Complication & No. of eyes \\
\hline 1 & Moderate post OP INF & 2 \\
\hline 2 & IOL DEC & 2 \\
\hline 3 & Severe PO INF (Fibrin) & 1 \\
\hline 4 & Visual axis opacification & 3 \\
\hline 5 & Corneal oedema & 1 \\
\hline 6 & Glaucoma & 1 \\
\hline 7 & Retinal detachment & $\mathbf{1 1}$ \\
\hline
\end{tabular}

Post op Inf- post-operative intrsuctions, IOL Dec-decenteration, PO Inf- Post operative infection

Overall majority of patients showed remarkable improvement in visual acuity (Table 4-7). Amblyopia was thought to be present in 20 patients and 17 of these patients showed good compliance with occlusion therapy after implantation surgery, resulting in improvement in visual acuity. Visual acuity obtained were correlated with the age of patient at time of primary surgery. Children who had early primary cataract surgery showed better final visual acuity, although difference was not statistically significant in the present study ( $p$ value 0.06). Comparison of visual outcome in traumatic versus congenital aphakia was made (Table 6). More patients with traumatic aphakia achieved 20/40 or better vision than did patients with congenital aphakia. Refractive result (in spherical equivalent) was calculated at first and last follow up visit (Table 4).

A comparison of the obtained refractive result with the refractive goal of the surgeon was made at 4 months after surgery, assuming that 4 months postoperatively the surgical wound would be stable. Mean targeted refraction was +2.09D. Mean difference of $-0.06 \mathrm{D}$ between targeted and actual refraction was observed (Table 5).

There were few patients in whom major deviations from goal occurred, of upto -5.00D. Comparison of pre-op and post op pachymetry and intra-ocular pressure was made, the difference was not statistically significant. 
Table 8 shows complications that occurred in the present study. Severe inflammation with fibrinous membrane was seen in 2 cases. In both cases it resolved with frequent dosage of topical prednisolone (every 1-2 hr.) and oral prednisolone. Visual axis opacification was seen in 1 case and Nd: YAG laser capsulotomy was enough to open a clear visual axis.

Less occurrence of visual axis opacification highlights the importance of sufficient primary posterior capsulorrhexis with anterior vitrectomy. Glaucoma developed in 1 case, in which IOP normalization was achieved with topical anti-glaucoma medication. IOL decentration was seen in 1 case but it was not significant enough to hamper functional vision. Retinal detachment was seen in 1 case and despite retinal detachment surgery visual outcome was poor.

\section{Discussion}

IOL implantation has become the most accepted mode of refractive correction after cataract extraction in children older than 1 year of age [9-12]. This has been possible because of advances in IOL surgery that include availability of high viscosity viscoelastics [13] improved IOL design [14] and posterior scleral beveled incision [15] that significantly reduces the incidence of complications that were encountered with the early attempts at IOL implantation in children. Autrata [16] et al reported better visual outcomes in children who had undergone IOL implantation than in those managed with contact lens.

If $20 / 80$ or better is accepted as a definition of good visual acuity [17] most of the patients in the present study did well. Visual acuity in $70 \%$ of our patients was 20/80 ( $\leq 0.6$ LOGMAR) or better. Awad et al [7] reported similar findings in their study. Shenoy [18] et al reported 20/40 vision in 54\% eyes. Beller [19] and coauthors and Gregg and Parks [20] showed that the earlier the surgical treatment, the better the functional results. In the present study didn't find any significant correlation between the age at primary surgery and visual outcome in congenital cataract (p-0.06). The mean age at the time of secondary IOL implantation in congenital aphakia was 43.2 months.

In the present study, children who had traumatic cataracts were also included and it is well established that visual acuity improvement is good in this group [21], unless traumatic cataract is accompanied by major posterior segment complications. There was a statistically significant difference in final visual acuity obtained after the IOL implantation surgery when traumatic versus nontraumatic aphakia was compared $(\mathrm{p}=0.001)$. These findings compare favorably with those of a previously reported series [22].

Amblyopia was seen in $60 \%$ patients post operatively which responded well to occlusion therapy. Awad et al [7] reported that children less than 4 years are more likely to develop amblyopia, the mean age of our patients was 54.15 months at the time of primary surgery. Also since traumatic cases were included in this study, 9 out of 12 had corneal scars which led to pre op stimulus deprivation amblyopia. Such cases did not respond well to occlusion therapy. The ideal site for IOL implantation is in the bag, as it keeps the lens well centered and keeps it sequestered from irritants from iris tissue. Sulcus implantation theoretically increases the risk of raised post op intraocular pressure and inflammation. Previous studies have shown that sulcus fixated IOLs work better in aphakic children [7].

This is due to the fact that the IOL can be supported on the peripheral anterior capsule remanants if a primary posterior capsulotomy was done during primary surgery. In the bag implantation in such cases can be difficult and fraught with complications.

Trivedi et al [2] compared the outcomes of secondary IOL implantation in children. They reported that none of the 29 eyes that were implanted with a PMMA sulcus fixated IOL developed decenteration. Foldable singlepiece IOLs are not recommended for sulcus fixation. Trivedi and colleagues [2] found that 4 eyes (28.5\%) with sulcus-fixated foldable IOLs developed clinically significant decenteration and required repositioning or exchange of IOL. Decenteration of IOL may be as a result of external factors, such as trauma or eye rubbing, or maybe the result of internal factors, such as size disparity between an IOL and the site of fixation, scarring, synechiae formation, and capsular contraction $(2,23-25)$.

In the present study non foldable 3 piece IOL was used and IOL decenteration was seen in only 1 case. Target refractions were variable, depending on the age of the patient at secondary IOL surgery and status of the fellow eye, but we found that we were able to achieve our postoperative refraction within a reasonable range. Our absolute mean PE was $-0.06 \pm 2.17$.

Nihalani et al [25] found mean PE of 0.9 \pm 0.9 . Moore et al [26] reported a mean PE of $1.64 \mathrm{D} \pm 1.58 \mathrm{D}$. These studies included patients who underwent in the bag as well as sulcus fixation, while our patients had only sulcus fixation, which may explain the difference 
observed. The variation may also be accounted for by the difference in age and clinical profile of the selected cases in the above mentioned studies as well as the use of different IOL power calculation formulae.

Finally, we evaluated the incidence of postoperative complications. Our measured complication rate was not higher than the previously reported complication rate. Glaucoma is the most common complication, having unclear pathophysiology. O'Keefe et al [27] have reported that posterior chamber IOL reduced the risk for post-op glaucoma.

Crinic and colleagues [28] found that $22 \%$ of eyes developed transient increase in IOP and 11\% developed chronic glaucoma after foldable secondary IOL implantation. The prevalence of glaucoma after congenital cataract surgery has been reported to range from $0 \%$ to $32 \%$ [29-31]. In the present study postoperative glaucoma developed only in $1(1.9 \%)$ eye.

Capsular opacification or visual axis opacification (VAO) is the second most common reported complication. Crinic et al [28] reported VAO in $9 \%$ of their sulcus positioned IOLs. KS Wood [32] and colleagues reported VAO in $5.4 \%$. In the present study VAO was found in only 1 eye $(1.9 \%)$.

Risk of retinal detachment is difficult to evaluate because of its late onset in most cases. Hiles and Watson [33] found retinal detachment in $6 \%$ of eyes. In the present study, 1 eye had retinal retinal detachment.

\section{Conclusion}

What was known before: 1. Aphakia during primary surgery is associated with fewer complications. 2. Previous studies have compared in-the-bag and sulcus implantations and reported the post-op complications, but have had short follow-up and selection bias towards sulcus implantation in the more complicated cases.

What this study adds: Long term follow up data on post op results and observed complications with sulcus implantation. Based on our results, this method seems to be the most suitable method for visual rehabilitation of aphakic children both after congenital cataract surgery and traumatic cataract extraction. Additionally the data suggest that this method is less fraught with complications, hence yielding better long term visual rehabilitation. The strength of this study is its longer follow up duration, and the consistency in surgical technique \& biometric measurements which were performed by single individuals respectively.
The retrospective nature of the study was its main limitation, as was the younger age of the patients which hampered consistent visual acuity assessments. Further long term studies with larger number of subjects are needed to further corroborate our findings

Author contributions: Saba Faruqui: Conceived and designed the study, reviewed the literature, collected the pre-op data, did analytical calculations and wrote the manuscript.

Rahul Jain: Collected pre op data, analysis, and preparation of tables.

Sarfraz Khan: Conceptualized and supervised the project, and performed all surgeries and post op evaluations.

\section{Funding: Nil, Conflict of interest: Nil Permission from IRB: Yes}

\section{References}

1. Zwaan J, Mullaney PB, Awad A, Al-Mesfer S, Wheeler DT. Pediatric intraocular lens implantation: surgical results and complications in more than 300 patients. Ophthalmol. 1998; 105 (1):112-9. DOI: https: //doi. org/10.1016/S0161-6420(98)91568-8

2. Trivedi RH, Wilson ME Jr, Facciani J. Secondary intraocular lens implantation for pediatric aphakia. J AAPOS. 2005;9(4):346-52.DOI:10.1016/j.jaapos. 2005. 02. 010

3. DeVARO JM, Buckley EG, Awner S, Seaber J. Secondary posterior chamber intraocular lens implantation in pediatric patients. Am J Ophthalmol. 1997; 123 (1): 24-30. DOI: 10.1016/s0002-9394(14) 70988-2

4. Biglan AW, Cheng KP, Davis JS, Gerontis CC. Secondary intraocular lens implantation after cataract surgery in children. Am J Ophthalmol 1997; 123: 22434. DOI: https:// doi.org/10. 1016/ S0002-9394 (14) $71040-2$

5. Biglan AW, Cheng KP, Davis JS, Gerontis CC. Results following secondary intraocular lens implantation in children. Trans Am Ophthalmol Soc. 1996;94:353-73.

6. Brady KM, Atkinson CS, Kilty LA, Hiles DA. Cataract surgery and intraocular lens implantation in children. Am J Ophthalmol. 1995;120(1):1-9. DOI:10. 1016/s0002-9394(14)73753-5 
7. Awad AH, Mullaney PB, Al-Hamad A, Wheeler D, Al-Mesfer S, Zwaan J. J. Secondary posterior chamber intraocular lens implantation in children. J Am Assoc Pediat Ophthalmol Strab. 1998;2(5):269-74.

8. Mackool RJ, Russell RS. Intracapsular posterior chamber intraocular lens insertion with posterior capsular tears or zonular instability. J Cataract Refract Surg. 1995;21(4):376-7. DOI: https://doi.org/10. 1016/ S0886-3350(13)80523-8

9. Wilson ME, Bluestein EC, Wang XH. Current trends in the use of intraocular lenses in children. J Cataract Refract Surg. 1994;20(6):579-83. DOI: https://doi.org/ 10.1016/S0886-3350(13)80642-6

10. Lin AA, Buckley EG. Update on pediatric cataract surgery and intraocular lens implantation. Curr Opin Ophthalmol. 2010; 21(1): 55-9. DOI: 10.1097/ICU. 0b $013 \mathrm{e} 32833383 \mathrm{cb}$.

11. Nihalani BR, Vasavada AR. Single-piece AcrySof intraocular lens implantation in children with congenital and developmental cataract. J Cataract Refract Surg. 2006;32(9):1527-34. DOI:10.1016/j. jcrs.2006.04. 021

12. Wilson ME, Trivedi RH. Choice of intraocular lens for pediatric cataract surgery: survey of AAPOS members. J Cataract Refract Surg. 2007;33(9):1666-8. DOI:10.1016/j.jcrs.2007.05.016

13. Khokhar SK, Pillay G, Agarwal E, Mahabir M. Innovations in pediatric cataract surgery. Indian $\mathrm{J}$ Ophthalmol. 2017;65 (3):210-216. DOI: 10.4103/ijo. IJO_860_16.

14. Hutchinson AK, Wilson ME, Saunders RA. Outcomes and ocular growth rates after intraocular lens implantation in the first 2 years of life. J Cataract Refract Surg. 1998;24(6):846-52. DOI: https://doi.org/ 10.1016/S0886-3350(98)80142-9

15. Agrawal R. Wound construction in small incision cataract surgery. Indian J Ophthalmol. 2010;58(1):85. DOI: $10.4103 / 0301-4738.58486$

16. Autrata R, Rehurek J, Vodicková K. Visual results after primary intraocular lens implantation or contact lens correction for aphakia in the first year of age. Ophthalmol.2005;219(2):72-9.DOI:10.1159/0000 83264

17. Birch EE, Stager DR. The critical period for surgical treatment of dense congenital unilateral cataract. Invest Ophthalmol Vis Sci. 1996;37(8):1532-8.
18. Shenoy BH, Mittal V, Gupta A, Sachdeva V, Kekunnaya R. Complications and visual outcomes after secondary intraocular lens implantation in children. Am J Ophthalmol. 2015;159(4):720-6. DOI: 10.1016/j. ajo. 2015. 01.002.

19. Beller R, Hoyt CS, Marg E, Odom JV. Good visual function after neonatal surgery for congenital monocular cataracts. Am J Ophthalmol. 1981;91 (5): 559-65. DOI:10.1016/0002-9394(81)90053-2

20. Gregg FM, Parks MM. Stereopsis after congenital monocular cataract extraction. Am J Ophthalmol. 1992; 114(3): 314-7. DOI: https://doi.org/ 10.1016/ S00029394 (14)71797-0

21. Bradford GM, Keech RV, Scott WE. Factors affecting visual outcome after surgery for bilateral congenital cataracts. Am J Ophthalmol. 1994;117 (1): 58-64. DOI:10.1016/s0002-9394(14)73015-6

22. De Ware IM, Buckley EG, Saeber J. Secondary posterior chamber intraocular lens implantation in paediatric patients, J Ophthalmol, 1997;123(1): 24-30. DOI: https://doi. org/10. 1016/ S0002-9394 (14) 70988-2

23. Wiesel TN, Hubel DH. Single-cell responses in striate cortex of kittens deprived of vision in one eye. $\mathrm{J}$ Neurophysiol. 1963; 26 (6):1003-17.DOI: 10.1152/ jn. 1963. 26.6.1003

24. Garza-Reyes M, Rodríguez-Almaraz M, RamírezOrtíz MA. Long-term visual results in congenital cataract surgery associated with preoperative nystagmus. Arch Med Res. 2000;31(5):500-4. DOI: https:// doi. org/ 10.1016/S0188-4409(00)00101-6

25. Nihalani BR, Vanderveen DK. Secondary intraocular lens implantation after pediatric aphakia. J AAPOS. 2011; 15(5):435-40. DOI: 10.1016/j.jaapos. 2011.05.019.

26. Moore DB, Zion IB, Neely DE, Roberts GJ, Sprunger DT, Plager DA. Refractive outcomes with secondary intraocular lens implantation in children. J AAPOS. 2009; 13(6):551-4. DOI: 10.1016/j.jaapos. 2009. 09.012.

27. O'Keefe M, Fenton S, Lanigan B. Visual outcomes and complications of posterior chamber intraocular lens implantation in the first year of life. J Cataract Refract Surg. 2001;27(12):2006-11.DOI: https://doi.Org /10. 1016/S0886-3350(01)00973-7 


\section{Original Research Article}

28. Crinic T, Weakly DR Jr, Stager D Jr, Felius J. Use of Acrysol acrylic foldable intraocular lens for secondary implantation in children. J AAPOS 2004; 8(2):151-5. DOI: https://doi.org/10.1016/j.jaapos. 2003. 10. 005

29. Chen TC, Walton DS, Bhatia LS. Aphakic glaucoma after congenital cataract surgery. Arch Ophthalmol. 2004 Dec;122(12):1819-25. DOI:10.1001/ archopht. 122.12.1819

30. Michaelides M, Bunce C, Adams GG. Glaucoma following congenital cataract surgery--the role of early surgery and posterior capsulotomy. BMC Ophthalmol. 2007;7(1):13. DOI:10.1186/1471-2415-7-13
31. Chak M, Rahi JS. Incidence and factors associated with glaucoma after surgery for congenital cataract: Findings from the British Congental Cataract Study. Ophthalmol. 2008;115(6):1013-18. DOI: 10.1016/j. ophtha.2007.09.002

32. Wood KS, Tadros D, Trivedi RH, Wilson ME. Secondary intraocular lens implantation following infantile cataract surgery: intraoperative indications, post operative complications. Eye 2016;30(9):11821186. DOI: $10.1038 /$ eye.2016.131

33. Hiles DA, Watson BA. Complications of implant surgery in children. J Am Intraocul Implant Soc. 1979; 5(1):24-32.

\section{How to cite this article?}

Faruqui S, Khan M.S, Jain R. Results of secondary ciliary sulcus fixated posterior chamber intra-ocular lenses in paediatric aphakia. Trop J Ophthalmol Otolaryngol.2019;4(3):181-189.doi:10.17511/jooo.2019.i03.01 